\title{
Road Fatalities in Karnataka (India): Need of Safe System Approach to Roads and Drivers Training
}

\author{
[Raj R.D. Kirori ${ }^{1}$, Sanklap Swami ${ }^{2}$, B.L. Swami ${ }^{3}$ ]
}

\begin{abstract}
India had reported 150,785 road fatalities in year 2016 and its Karnataka state appeared at $4^{\text {th }}$ rank with 11,133 road fatalities in 44403 road crashes. Age group below 35 years is at most risk with 59 percent share in fatalities in Karnataka. Road engineering is a major road safety issue as Karnataka National \& State Highways reported 65 percent of the state road fatalities. Road junctions are critical locations from safety point of view which claimed 3313 lives, 30 percent of fatalities.
\end{abstract}

Drivers killed in road crashes in Karnataka were 32 percent of fatalities ( 3587 drivers). It is a matter of grave concerns that 32 percent drivers-killed were young drivers below 25 years age. At this age decision making capacity in critical conditions is biologically in developing stage. The facts identify need of strengthening the system of drivers' training.

Drivers' fault was reported in 88 percent fatal road crashes in Karnataka. Investigations solely blame drivers in most road crashes and silent about possible faults/roles of service providers in a road crash whereas driver is responsible only for driving and traffic rules. Concept of 'safe system approach' to reduce fatalities is yet to be recognized in India for shared responsibility of the service providers (e.g. road agency, driving license authority, enforcement agency).

Safe system approach based framework is proposed for stakeholder service providers. Approach to road safety engineering is focused on forgiving designs, review of critical safety elements like junctions, school zones and routes, pedestrian facilities, safe corridor practices. Measures for strengthening of drivers training have been discussed for traffic parks to make publicity of traffic signs, driving rules and procedures of driving license and capacity building of training schools and implementation of public awareness and education campaign. Upgraded enforcements are proposed with additional resources like speed interceptors, breath analyzers to curb drunken driving and hydraulic cutters for quick recovery of crash victims.

Keywords-road injuries, road safety engineering, safe system approach, pedestrain safety, drivers training, enforcement

Raj R.D. Kirori, Ph. D. Scholar,

Department of Civil Engineering,

Malaviya National Institute of Technology, Jaipur-302017, India

Sankalp Swami,

Highway Engineer,

Avanza Engineering Private Ltd., Jaipur-302021, India

B.L. Swami, Professor,

Department of Civil Engineering,

Malaviya National Institute of Technology, Jaipur-302017, India 